\title{
DNA BARCODING OF COMMON MALAYSIAN SPIDERS USING THE CYTOCHROME OXIDASE I (COI) GENE
}

\author{
KEK CHIAN KOAY ${ }^{1}$, AHMAD MUKHLIS ABDUL RAHMAN ${ }^{1 *}$, JOHAN ARIFF MOHTAR ${ }^{1 *}$, \\ NURUL AIN HARMIZA ABDULLAH ${ }^{1}$, ANWARDI JAMIL ${ }^{1}$ and \\ MOHD MUSHAHRIL ABDUL SHUKOR ${ }^{2}$ \\ ${ }^{1}$ Department of Chemical Engineering Technology, Faculty of Engineering Technology, \\ Universiti Malaysia Perlis, 02100 Padang Besar, Perlis, Malaysia \\ ${ }_{2}^{2}$ Perbadanan Bekalan Air Pulau Pinang Sdn. Bhd., Loji Saringan Air Itam Jalan Air Itam \\ 11500 Air Itam, Pulau Pinang, Malaysia \\ *E-mail:mukhlis@unimap.edu.my or johanariff@unimap.edu.my
}

Accepted 22 September 2020, Published online 25 October 2020

\begin{abstract}
For the last twenty years, many newly described spiders were collected from Malaysia and in fact, more than 11,000 species were recorded in Peninsular Malaysia as well as in Sabah and Sarawak states. Scientists have put an immense effort on untangling the spider biology from its physical structure and behavior to silks and venoms. However, working with spiders is impeded by the difficulties in species identification via solely morphological methods. Thus, DNA barcoding is an alternative technique that employs standard fragment to facilitate species identification. Isolation of genomic DNA from three Malaysian spiders were performed using NucleoSpin ${ }^{\circledR}$ DNA insect extraction kit. Amplification of reference mitochondrial cytochrome oxidase I (COI) gene employing PCR with two set of primers followed by the DNA sequencing and validation through phylogenetic analysis were carried out. The commercial extraction kit was effective for the recovery of good quality of intact genomic DNA band as indicated by the integrity analysis. Both set of primers successfully amplified $100 \%$ of the samples with approximately $600-700 \mathrm{bp}$ of PCR products. The obtained sequences (610 bp to $692 \mathrm{bp}$ ) were compared with the sequences available in Gene Bank. BLAST and phylogenetic analysis revealed that the analyzed individual samples belong to Nephila pilipes, Neoscona nautica and Crossopriza lyoni, respectively. Phylogenetic analysis provided unique insight into the evolutionary relationship of each analyzed sample. This study aids in an accurate identification of the selected local spider species at molecular level using the COI gene.
\end{abstract}

Key words: DNA, barcoding, spiders, phylogenetic, identification

\section{INTRODUCTION}

Spiders (araneae) are air-breathing arthropods that possess four pairs of legs and a pair of chelicerae equipped with venom-glandular fangs. They are the largest order of arachnids and rank seventh in total species diversity among all other organisms (Sebastian \& Peter, 2009). Their population is ubiquitous on every continent except for Antarctica, and have established in nearly every habitat with the exceptions of air colonization (Foelix, 2011). Spiders are known to play an important role in the terrestrial ecosystem. They are one of the noteworthy groups of carnivorous invertebrates of insects, fishes, frogs, lizards, snakes and even mammals like

\footnotetext{
* To whom correspondence should be addressed.
}

bats (Wise, 1993). Moreover, their economic importance in integrated pest control program is widely acknowledged (Sebastian \& Peter, 2009). In recent years, spiders have become one of the highlights in applied science studies. With the ability to spin up to seven types of silk threads to suit their biological needs, researchers have now steered the direction to investigating the spider silk fiber for its remarkable physico-chemical properties (Romer \& Scheibel, 2008).

Due to these ecological and economical significances, spiders have been well studied in the past and their taxonomy, in general, has been well established. In fact, they are considered as one of the most diverse arthropod groups with at least 47,325 identified species and 116 described families. However, there is very little creditable 
research been done in establishing the molecular variations (White et al., 1990) as the systematic and taxonomy of spiders has always been problematic due to the difficulties in morphology-based identification (Jocque, 2002). Morphological identification of spiders can sometimes be barely performed. It is often complicated by the strict requirement of adult individuals (Coddington \& Levi, 1991), sexual dimorphisms and variation in genitalia morphology (Huber \& Gonzalez, 2001). However, spider species contain genomes that represent a potential non-invasive source of DNA for conservation and genetic analysis (Max et al., 2016). The use of genetic markers in the DNA spider, which are short nucleotide sequences from a standardized region of the genome, has been regarded as a promising approach to resolve this taxonomic dilemma. DNA sequences have become the major source of the information for developing our understanding of evolutionary genetic relationships in line with the advancement in sequencing and computational technologies (Tibayrenc, 2005).

Hence, molecular identification of spider is more precise and trustworthy as it provides an excellent resource for genetic studies across the families. Therefore, this project aims to evaluate the genetic identity of the selected spiders namely, Nephila pilipes, Neoscona nautica and Crossopriza lyoni using amplification of genomic DNA sequence based on the primer pair method in combination with DNA sequencing and phylogenetic analysis. These species are commonly ubiquitous and most importantly, their residence are in close proximity to human in Malaysia. This knowledge provides a far greater significance for our future understanding of the uniqueness of these spiders for potential biotechnology applications.

\section{MATERIALS AND EXPERIMENTAL}

\section{Spider sampling}

Sampling was conducted from June to September 2018. Spiders were collected from various localities around northern regions specifically in Perlis and Penang. A total of ten adult $N$. pilipes were captured by net sweeping method in Kampung Batu Kecil, Sungai Pinang, Balik Pulau, Penang. Meanwhile a total of 20 adult $N$. nautica and 30 adult C. lyoni were respectively, sampled using small bottles from abandoned buildings and drains at UniCITI Alam Campus, Sungai Chuchuh, Padang Besar, Perlis. During the sampling, only healthy spiders were chosen and used for the molecular analysis. They were subsequently identified based on the morphological characters of various body parts as outlined in Table 1 . The spiders were temporarily transferred into plastic bottles and starved for $24 \mathrm{hr}$ prior to extraction.

\section{Genomic DNA extraction}

Molecular identification of spiders begins with the isolation of target genomic (DNA) using a number of extraction methods such as TriZOL, cetyl-trimethyl ammonium bromide (CTAB) and phenol-chloroform (Anjali, 2015). In this study, genomic DNA from the adult spiders was recovered using the NucleoSpin ${ }^{\circledR}$ DNA insect extraction kit (Macherey-Nagel, Germany) in accordance to the manufacturer's manual with slight modifications. The spiders were initially subjected to slow freezing to reduce the metabolism rate and put them to death. $40 \mathrm{mg}$ cephalothorax tissues of $N$. pilipes and from the whole bodies of $N$. nautica as well as C. lyoni, respectively. They were washed and rinsed in distilled water to remove dirt prior to

Table 1. Morphological characters of N. pilipes, N. nautica and C. Iyoni

\begin{tabular}{|c|c|c|c|}
\hline Parameter Species & Nephila pilipes & Neoscona nautica & Crossopriza lyoni \\
\hline Primary color & $\begin{array}{l}\text { Black or yellowish- } \\
\text { black in color }\end{array}$ & Light brown in color & Dark brown in color \\
\hline Cephalothorax & $\begin{array}{l}\text { Carapace shape is } \\
\text { longer than wide }\end{array}$ & $\begin{array}{l}\text { Carapace is more or less } \\
\text { circular from dorsal view }\end{array}$ & $\begin{array}{l}\text { Carapace shape is } \\
\text { longer than wide }\end{array}$ \\
\hline Abdomen & Longer than wide & $\begin{array}{l}\text { Quadrilateral shape from } \\
\text { lateral view }\end{array}$ & $\begin{array}{l}\text { Almost spherical to heart } \\
\text { shaped with an arrow } \\
\text { mark on it }\end{array}$ \\
\hline Legs & $\begin{array}{l}\text { Long legs and some } \\
\text { with yellow patches } \\
\text { on legs joints }\end{array}$ & $\begin{array}{l}\text { Extremely long fragile } \\
\text { legs with darker patches } \\
\text { on knee segments }\end{array}$ & $\begin{array}{l}\text { Relatively short legs with } \\
\text { prickles }\end{array}$ \\
\hline Average length of the body & $26 \mathrm{~mm}$ & $8 \mathrm{~mm}$ & $7 \mathrm{~mm}$ \\
\hline Average length of the legs & $89 \mathrm{~mm}$ & $54 \mathrm{~mm}$ & $12 \mathrm{~mm}$ \\
\hline
\end{tabular}


homogenization. The dried samples were ground using a sterile micropestle in $100 \mu \mathrm{L}$ of deionized water for $5 \mathrm{~min}$ in ice. The pulp was further homogenized following the addition of $200 \mu \mathrm{L}$ of MG buffer. In order to purify the pulp from contaminating proteins, $50 \mu \mathrm{L}$ of proteinase $\mathrm{K}$ (20 $\mathrm{mg} / \mathrm{mL}$ ) was added. The tube was inverted for several times to mix and incubated for $5 \mathrm{~min}$ at room temperature. $600 \mu \mathrm{L}$ of $\mathrm{MG}$ Buffer was pipetted into the tubes with several times of inversions. The samples were then centrifuged at $11,000 \times \mathrm{g}$ for 30 seconds to precipitate insoluble debris. The supernatant was transferred onto the NucleoSpin ${ }^{\circledR}$ DNA Insect column and washed two times with $500 \mu \mathrm{L}$ of Buffer BW and Buffer B5, respectively prior to drying. Column washing and drying were carried out at $11,000 \times \mathrm{g}$ for $30 \mathrm{~s}$. Following incubation with $40 \mu \mathrm{L}$ of Elution Buffer $\mathrm{E}$ for $5 \mathrm{~min}$ at room temperature, the DNA was recovered from the column matrix at $11,000 \times \mathrm{g}$ for $30 \mathrm{~s}$. Finally, the nucleic acids were treated with 10 $\mu \mathrm{L}$ of Rnase $\mathrm{A}(10 \mathrm{mg} / \mathrm{mL})$ at ambient temperature for $10 \mathrm{~min}$ and stored at $-20^{\circ} \mathrm{C}$ upon use.

\section{Polymerase chain reaction (PCR) amplification}

Several primers pairs were applied to obtain the target sequence of DNA from different samples. The mitochondrial COI gene was amplified by Polymerase Chain Reaction (PCR) using the primers of LCO1490A (5'-GGTCAACAAATCATAAAGA TATTGG-3'), Chelicerate Reverse 1 (5'-CCTCCT CCTGAAGGGTCAAAAAATGA-3') and Chelicerate Reverse 2 (5'-GGATGGCCAAAAAATCAAAAT AAATG-3') (Rowan \& Paul, 2005). The reaction mixture for PCR consisted of master mix, template DNA, forward and reverse primers, nuclease-free water and thermal cycler to amplify the target sequence of DNA. EconoTaq ${ }^{\circledR}$ Plus Green Master Mix consisted of 0.1 units $/ \mu \mathrm{L}$ of EconoTaq DNA Polymerase, reaction buffer ( $\mathrm{pH} 9), 400 \mu \mathrm{M}$ dCTP, $400 \mu \mathrm{M}$ dTTP, $3 \mathrm{mM} \mathrm{MgCl}$, and a proprietary mix of PCR enhancer or stabilizer and blue and yellow tracking dyes (Lucigen, 2016). PCR amplification was conducted in a total volume of $25 \mu \mathrm{L}$ of reaction buffer, containing DNA template, primers, nuclease-free water and EconoTaq $2 \times$ Master Mix. The reaction mixture was then subjected to PCR on a thermal cycler. Initially, it was preheated to $94^{\circ} \mathrm{C}$ prior to operation. Initial denaturation of PCR amplification commenced at $94^{\circ} \mathrm{C}$ for $1 \mathrm{~min}$ to activate the EconoTaq DNA Polymerase and to ensure the double strand DNA (dsDNA) molecules were broken down into single strands for amplification. Denaturation step was set a $94^{\circ} \mathrm{C}$ for $45 \mathrm{~s}$ and annealing step at $50^{\circ} \mathrm{C}$ for $45 \mathrm{~s}$. Sequence extension was performed at $72^{\circ} \mathrm{C}$ for $30 \mathrm{~s}$ and the final extension was at $72^{\circ} \mathrm{C}$ for 5 min with a total number of 35 cycles. The amplified fragments were then analyzed by gel electrophoresis (Rhennetta, 2015).

\section{Gel analysis of genomic DNA and PCR product integrity}

In order to examine the quality of the genomic DNA, the extracts were subjected to agarose gel electrophoresis. One percent gel was used and stained with ethidium bromide for DNA visualization. One microliter of loading dye was added into $5 \mu \mathrm{L}$ of DNA sample and allowed to mix. Four microliters of $1 \mathrm{~kb}$ DNA ladder (Biotechrabbit, USA) was pipetted carefully into the first lane of the submerged gel to represent as a DNA marker. After loading all the DNA samples into the subsequent wells, the electrophoresis was executed at 90 volt for $40 \mathrm{~min}$. For PCR products, they were separated using 2\% agarose gel to resolve small amplified DNA fragments between 100-1000 bp. Two microliters of PCR products were loaded into respective wells. Gel electrophoresis was then conducted for $60 \mathrm{~min}$ at $75 \mathrm{~V}$. The integrity and the approximate size of the genomic DNA band as well as the PCR products for each species were accessed using the Gel Documentation System (Biorad).

\section{DNA sequencing}

To obtain the complete sequence of the PCR products, the fragments were subjected to Sanger sequencing. Initially, the PCR products were purified and quantified by gel electrophoresis. BigDye Terminator V3.1 Cycle Sequencing Kit (ABI) was used for sequencing in a single reaction of one direction and followed by the automated DNA sequencing by electrophoresis. Chromatogram of DNA data were analyzed involving the combination, edition and extraction to DNA sequences using ChromasPro 1.5 software.

\section{Phylogenetic analysis of the spider species}

The amplified fragments were trimmed and checked via sequence alignment in the gene bank database of National Centre of Biotechnology Information (NCBI). They were compared with those available in Gene Bank in order to determine the similarity of each sample using Basic Local Alignment Search Tool (BLAST). The BLAST results showed the percentage of accuracy that was similar to the sequences of spider species deposited in NCBI. The BLAST is a tool applied extensively in sequencing project. Phylogenetic tree was constructed using Clustal Omega (ver. 1.2.1). The phylogenetic tree revealed the taxonomy of the spider species. 


\section{RESULTS AND DISCUSSION}

\section{Analysis of extracted genomic DNA}

Isolation of genomic DNA from the three spiders was conducted by solid-phase extraction method using NucleoSpin ${ }^{\circledR}$ DNA insect extraction kit. Spin column aims to isolate high quality and yield of total DNA from tissue samples by allowing the nucleic acid to bind onto the immobilized silica matrix and further eluted for recovery. The extraction kit was proven reliable to be used in this study as it was able to maintain the integrity and size of the genomic DNA. Nevertheless, low degree of RNA contamination was observed throughout the experiment and was overcome by
RNAse pretreatment. Gel analysis of the genomic DNA from each species is illustrated in Figure 2 to 4 . From the figures, all genomic DNA were illuminated in one large band of more than $10 \mathrm{~kb}$ (Pei et al., 2012). Genomic DNA is usually large and has heavier molecular weight. As a result, it migrates in a shorter distance through the $1 \%$ gel and appears above the $1 \mathrm{~kb}$ DNA marker. Furthermore, no sign of DNA smearing was detected. This finding was in line with Ramakrishnaiah et al. (2015) who used the spin column method to extract high quality genomic DNA from five spider species namely, Hersilia savignyi, Crossopriza lyoni, Artema atlanta, Cirtophora citricola and Neoscona bengalensis.

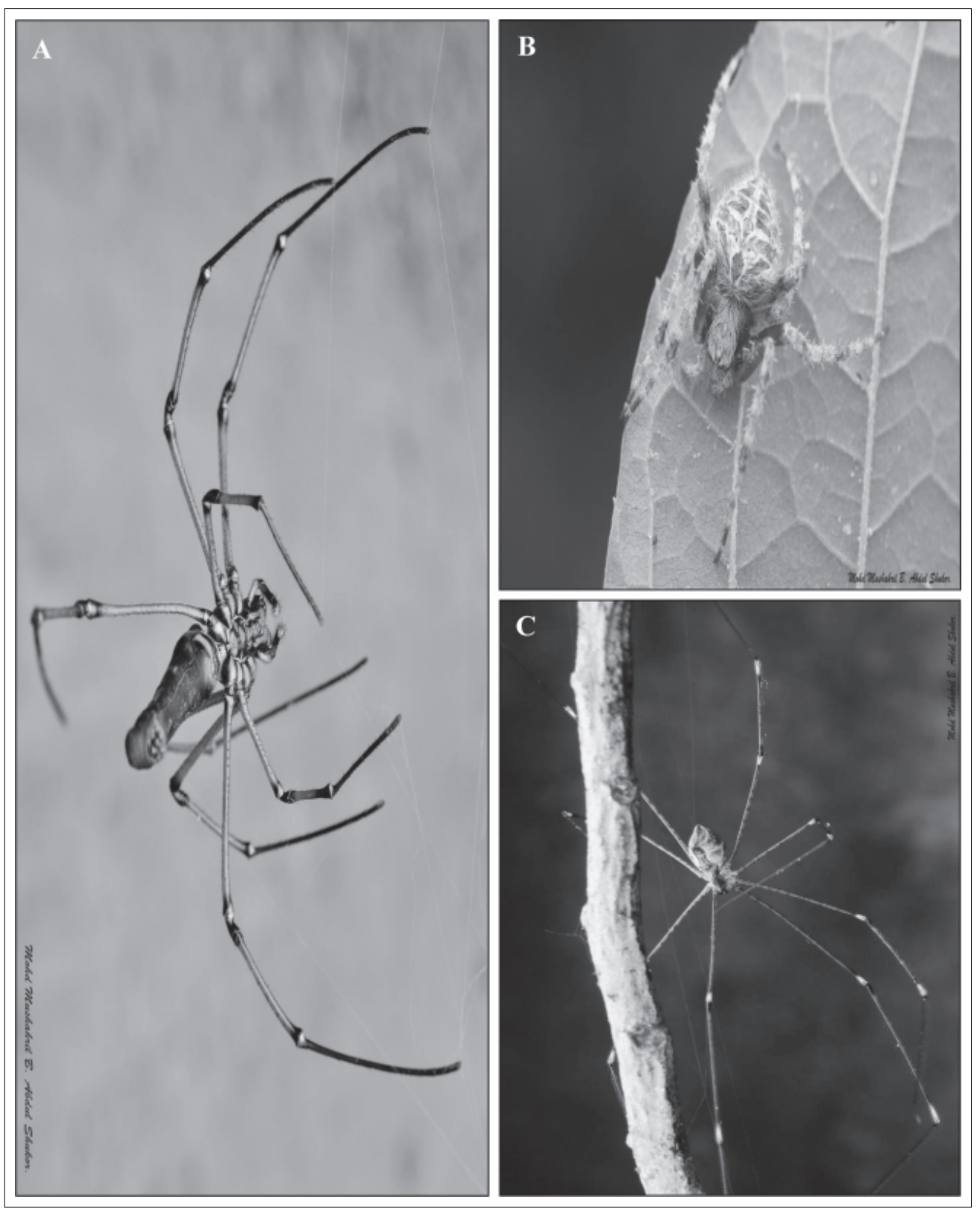

Fig. 1. The three spider species identified in this study: (A) Nephila pilipes isolate JTKK1, (B) Neoscona nautica isolate JTKK1 and (C) Crossopriza lyoni isolate JTKK1. 


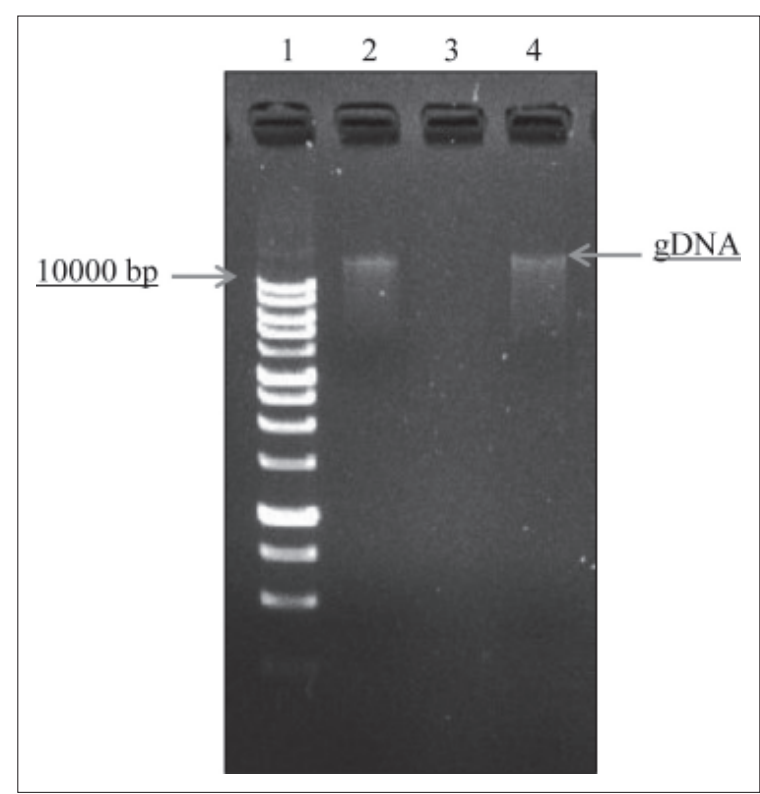

Fig. 2. Gel analysis of genomic DNA integrity from the cephalothorax tissue of Nephila pilipes. (Lane 1: $1 \mathrm{~kb}$ marker; Lane 2 \& 4: Nephila pilipes genomic DNA band; Lane 3: negative control). Note: $\mathrm{bp}=$ base pairs; gDNA = genomic DNA.

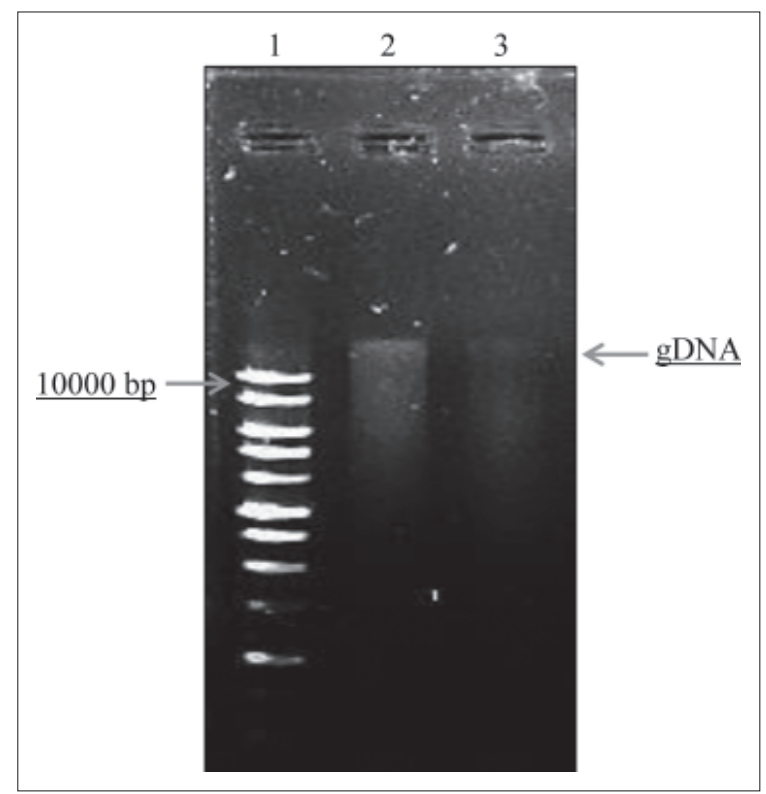

Fig. 4. Gel analysis of genomic DNA integrity from the whole body of Neoscona nautica. Lane 2 and 3 show the size of the DNA of more than $10 \mathrm{~kb}$. (Lane 1: $1 \mathrm{~kb}$ marker; Lane 2 \& 3: Neoscona nautica genomic DNA band). Note: $\mathrm{bp}=$ base pairs; gDNA = genomic DNA.

\section{Analysis of PCR products}

A standard forward primer LCO1490A was employed in combination with the two reverse primers namely Chelicerate Reverse 1 and Chelicerate Reverse 2 to amplify the mitochondrial

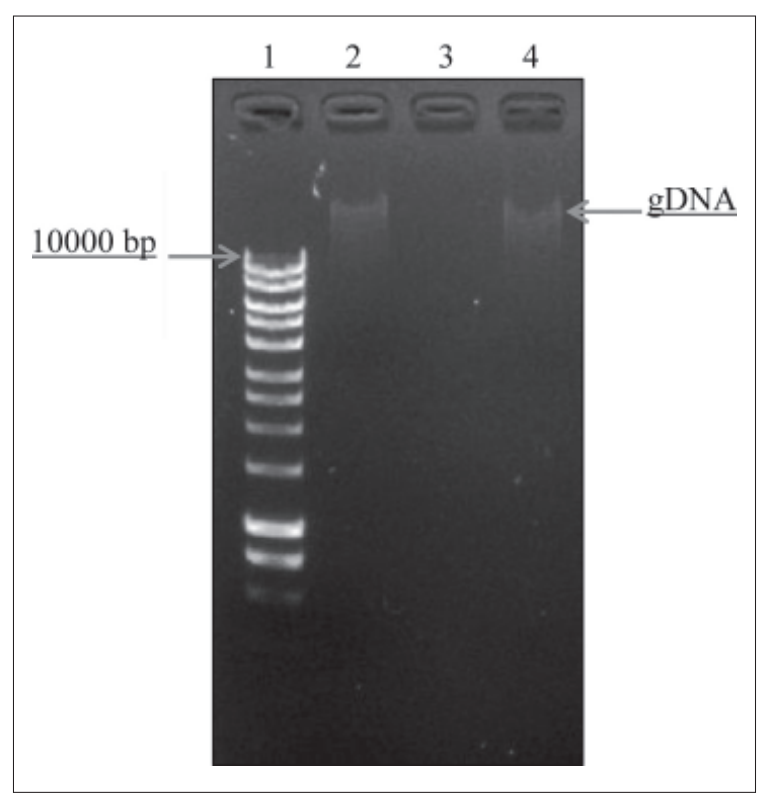

Fig. 3. Gel analysis of genomic DNA integrity from the whole body of Crossopriza lyoni with the size of more than $10 \mathrm{~kb}$. (Lane 1: $1 \mathrm{~kb}$ marker; Lane 2 \& 4: Crossopriza lyoni genomic DNA band; Lane 3: negative control). Note: $\mathrm{bp}=$ base pairs; gDNA = genomic DNA.

cytochrome oxidase I (COI) gene of three spider species. PCR fragments were separated by electrophoresis on a $2 \%$ agarose gel in TAE buffer as shown in Figure 5 and Figure 6. Direct visualization on the gel indicates that all the PCR products obtained were highly pure with the absence of primer-dimers. This implies the absence of DNA contaminants during the preparation of PCR analysis. From the gel analysis, it could be noted that the approximate size of the bands fell in the range between $550 \mathrm{bp}$ to $700 \mathrm{bp}$. In addition, it was also found that each of the fragment appeared as a consistently single amplified, clear and sharp band. Table 2 displays the expected size and the percentage of the sample amplified for each primer pairs in each species. It can be inferred that the primer pairs which are the combination form of LCO1490A-Chelicerate Reverse 1 and LCO1490AChelicerate Reverse 2 were expected to amplify DNA sequences at approximately $660 \mathrm{bp}$ as outlined by Rowan and Paul (2015). Consequently, in line with the estimated PCR products size, the amplified DNAs were considered as the successful fragments that were suggestible for sequencing. LCO1490A is a universal primer that was originated from the design of three coding and six anticoding strands by comparing highly conserved regions of mitochondrial cytochrome c oxidase subunit I (COI) genes across 15 taxa (Sharma \& Kobayashi, 2014). In a previous study by Rhennetta (2015), she reported that the use of the universal primer with 


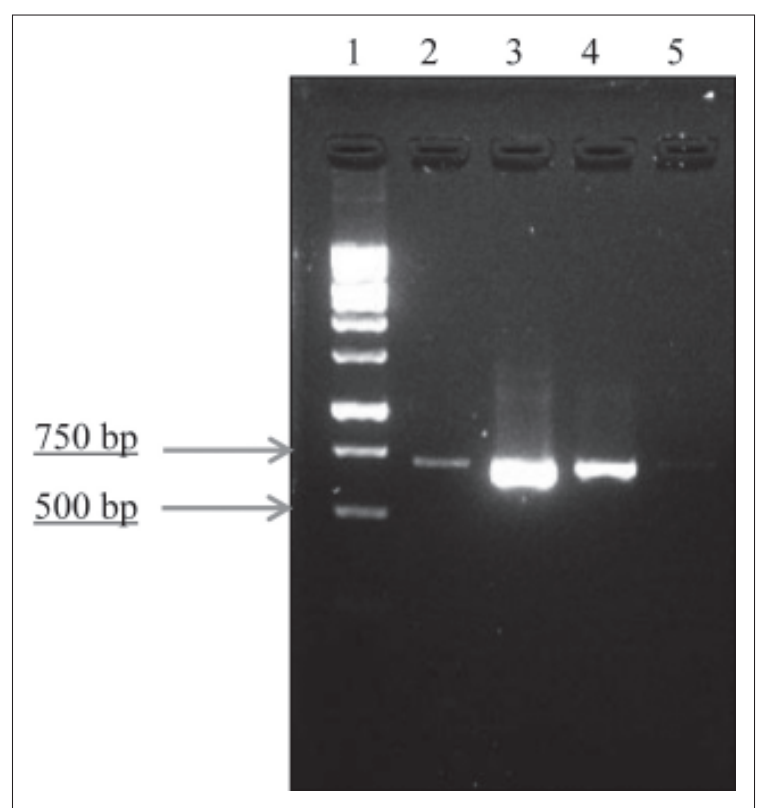

Fig. 5. Electrophoresis of PCR products for the three samples amplified with primer pairs combination of LCO1490A-Chelicerate Reverse 1 (Lane 1: 100 bp marker; Lane 2: Nephila pilipes isolate JTKK1; Lane 3: Neoscona nautica isolate JTKK1; Lane 4: Crossopriza lyoni isolate JTKK1; Lane 5: negative control). Note: $\mathrm{bp}=$ base pairs.

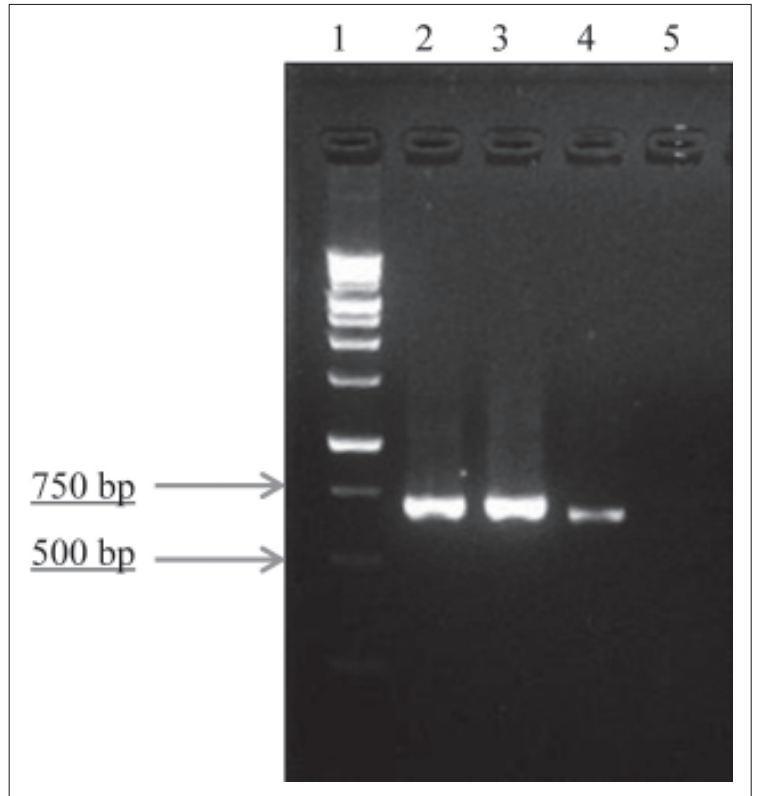

Fig. 6. Electrophoresis of PCR products for the three samples amplified with primer pairs combination of LCO1490A-Chelicerate Reverse 2 (Lane 1: $1 \mathrm{~kb}$ marker; Lane 2: Nephila pilipes isolate JTKK1; Lane 3: Neoscona nautica isolate JTKK1; Lane 4: Crossopriza lyoni isolate JTKK1; Lane 5: negative control). Note: $\mathrm{bp}=$ base pairs.

Table 2. The expected length of the PCR products and the percentage of sample amplified

\begin{tabular}{|c|c|c|c|c|c|}
\hline \multirow[b]{2}{*}{ Primer Sets } & \multicolumn{3}{|c|}{ Spider Samples } & \multirow{2}{*}{$\begin{array}{c}\text { No. of } \\
\text { Sample } \\
\text { Amplified }\end{array}$} & \multirow{2}{*}{$\begin{array}{c}\text { Percentage } \\
\text { of Samples } \\
\text { Amplified }\end{array}$} \\
\hline & N. pilipes & C. Iyoni & N. nautica & & \\
\hline LCO1490A and Chelicerate Reverse 1 & $660 \mathrm{bp}$ & $660 \mathrm{bp}$ & $660 \mathrm{bp}$ & $3 / 3$ & $100 \%$ \\
\hline LCO1490A and Chelicerate Reverse 2 & $660 \mathrm{bp}$ & $660 \mathrm{bp}$ & $660 \mathrm{bp}$ & $3 / 3$ & $100 \%$ \\
\hline
\end{tabular}

combination with other eight types of primers has successfully amplified the DNA fragment of nine different species of spiders in South Dakota, USA.

\section{DNA sequencing and basic local alignment search tool (BLAST)}

A total of six samples were subjected to DNA sequencing. The amplified COI fragments were sequenced to assign the specimens to their species-specific DNA sequences using the BLAST algorithm (Altschul et al., 1990). The sequences were successfully detected and sequenced. From the chromatogram analysis, the exact orders of the DNA barcodes for $N$. pilipes, $N$. nautica and $C$. lyoni which were previously amplified by the primer pairs of LCO1490A-Chelicerate Reverse 1 were obtained from the highest peak (Figure 7-9). In this paper, only the DNA sequences amplified by LCO1490AChelicerate Reverse 1 are reported. The generated sequence data analysis for the primer pairs corresponds to $651 \mathrm{bp}$ for $N$. pilipes, $657 \mathrm{bp}$ for $N$. nautica and 656 bp for C. lyoni, respectively. The sequence data is used for species discrimination by blasting in the database and to resolve the phylogenetic relationship.

Table 3 summarizes the exact length of PCR products obtained through Sanger sequencing analysis. The sequences up to $650 \mathrm{bp}$ of $\mathrm{CO} 1$ gene were successfully recovered from the six samples. The average length of DNA amplified was approximately $660 \mathrm{bp}$ which was in line with the corresponding band on the agarose gel. For the primer pairs of LCO1490A-Chelicerate Reverse 1 and LCO1490A-Chelicerate Reverse 2, the length of the PCR products amplified ranged from $651 \mathrm{bp}$ to $704 \mathrm{bp}$ for most of the tested samples. Both primer pairs amplified only the targeted reference region of approximately $660 \mathrm{bp}$ of $\mathrm{CO} 1$ genes and they did not exhibit cross-reaction. The DNA sequencing data match with the band size analysed from the gel analysis. The recovered sequences were also searched against and compared with the 
AGCTGCTATAGTGAGGAACTGCTATAAGAGTTTTGATTCGGATTGAATTGGGTCAAGTTGGAAGATTAT TAGGAGATGATCAGTTATATAATGTAATTGTTACAGCTCATGCTTTTGTAATAATTTTTTTTATGGTTATA CCTATTTTAATTGGGGGTTTTGGTAATTGATTGGTTCCTTTAATATTAGGGGCTCCTGATATAGCTTTTCC TCGCATAAATAATTTAAGATTTTGATTATTACCCCCTTCATTATTTTTATTATTTATTTCATCAATAGTAGA AATAGGTGTAGGTGCAGGATGAACTGTATATCCTCCATTAGCTTCTTTAGAAGGCCATGCTGGAAGATC TGTAGATTTTGCTATTTTTTCTTTACATTTAGCGGGTGCTTCTTCAATTATAGGGGCTATTAACTTTATTTC AACAATTTTAAATATGCGATCATATGGAATATCTATAGAGAAAGTTCCTTTATTTGTATGATCTGTATTG ATTACTGCTGTATTACTTTTACTTTCATTACCAGTATTAGCTGGTGCAATTACAATATTATTAACTGATCG AAATTTTAATACTTCATTTTTTGACCCTTCAGGAGGAGGCGGATATAC

Fig. 7. DNA barcode of Nephila pilipes isolate JTKK1 amplified by the primer pairs of LCO1490A-Chelicerate Reverse 1.

TTTATTTTTGGGGCATGGGCTGCATGATAGGAACAGCTATAAGAGTATTAATTCGAATTGAATTAGG TCAACCTGGAAGATTTATAGGTGATGATCAATTATATAATGTAATTGTAACTGCTCATGCTTTTGTAA TAATTTTTTTTATAGTAATACCAATTTTAATTGGTGGATTTGGAAATTGATTAGTACCTTTAATATTAG GGGCTCCTGATATAGCATTTCCTCGAATAAATAATTTAAGATTTTGATTATTGCCACCTTCATTATTTT TATTAATTATTTCTTCATTAGTAGAAATAGGAGTAGGGGCAGGATGAACAGTATATCCACCTTTAGC TGGATTAGAAGGTCATGCTGGTAGATCTGTAGATTTTGCTATTTTTTCTTTACATTTAGCTGGTGCTT CTTCAATTATAGGAGCTATTAATTTTATTTCAACAATTATTAATATACGATTTTATGAAATAACTATA GAAAAGGTTCCTTTATTTGTATGATCTGTATTAATTACAGCGGTTTTATTATTATTATCTTTACCTGTA TTAGCAGGTGCAATTACTATATTATTAACTGATCGAAATTTTAATACTTCATTTTTTGACCCTCC

Fig. 8. DNA barcode of Neoscona nautica isolate JTKK1 amplified by the primer pairs of LCO1490A-Chelicerate Reverse 1.

ATTTTCGGATTTGAGCAGGAATAATTGGGACTTCTTTAAGTTTATTAATTCGAGCAGAATTAGGTAA CCCAGGATCTTTAATTGGGGATGACCAAATTTATAATACTATTGTTACTGCTCATGCTTTTATTATAA TTTTTTTCATAGTAATGCCAATTATAATTGGAGGATTTGGAAATTGACTTGTACCTTTAATATTAGGA GCTCCAGATATAGCATTCCCACGTATAAATAATATAAGATTTTGATTACTTCCACCTTCTATTATATT ACTAATCTCAAGAAGAATCGTAGAAAATGGAGCTGGAACTGGATGAACAGTTTATCCTCCTTTATC TTCTAATATTGCCCATGGAGGAAGTTCAGTAGATTTAGCAATTTTCTCCTTACATTTAGCCGGTATTT CTTCAATTTTAGGGGCAATTAATTTCATCACAACAATTATTAATATACGACTTAATAACATATCATTT GATCAATTACCATTATTTGTGTGAGCTGTAGGAATTACAGCTTTTTTATTATTATTATCACTACCTGTA TTAGCAGGAGCTATTACTATATTATTAACTGATCGAAATTTAAATACTTCATTTTTTGACCCTCAGGG GAGGAAGC

Fig. 9. DNA barcode of Crossopriza lyoni isolate JTKK1 amplified by the primer pairs of LCO1490A-Chelicerate Reverse 1.

Table 3. The exact length of the PCR products amplified from each primer pairs

\begin{tabular}{lcc}
\hline \multirow{2}{*}{ Samples } & \multicolumn{2}{c}{ Primer Sets } \\
\cline { 2 - 3 } & $\begin{array}{c}\text { LCO1490A \& Chelicerate } \\
\text { Reverse 1 }\end{array}$ & $\begin{array}{c}\text { LCO1490A \& Chelicerate } \\
\text { Reverse 2 }\end{array}$ \\
\hline Nephila pilipes & $651 \mathrm{bp}$ & $701 \mathrm{bp}$ \\
Neoscona nautica & $657 \mathrm{bp}$ & $701 \mathrm{bp}$ \\
Crossopriza Iyoni & $656 \mathrm{bp}$ & $704 \mathrm{bp}$ \\
\hline
\end{tabular}

available sequences in NCBI database by BLAST algorithm for species identification. From Table 4, DNA sequences were generated for the three samples and subsequently confirmed the identity of the three spiders. Hence, the selected spiders in this study were denoted as Nephila pilipes isolate JTKK1, Neoscona nautica isolate JTKK1 and Crossopriza lyoni isolate JTKK1 (Figure 1). The amplified DNA sequences of Nephila pilipes isolate JTKK1 and Neoscona nautica isolate JTKK1 by LCO1490AChelicerate Reverse 1 primer pair show 99\% match to that of in the database. However, only the DNA fragment of Crossopriza lyoni displays $73 \%$ similarity to the sequence available in Gene Bank. 
Table 4. The BLAST result for the amplified products using the primer pairs of LCO1490A- Chelicerate Reverse 1

\begin{tabular}{|c|c|c|c|c|c|}
\hline Samples & Description & $\begin{array}{l}\text { Maximum } \\
\text { Score }\end{array}$ & $\begin{array}{l}\text { Total } \\
\text { Score }\end{array}$ & $\begin{array}{l}\text { Query } \\
\text { Score }\end{array}$ & Identity \\
\hline $\begin{array}{l}\text { Nephila pilipes } \\
\text { isolate JTKK1 }\end{array}$ & $\begin{array}{l}\text { Nephila pilipes isolate, cytochrome oxidase } \\
\text { subunit I (COI) gene, partial genome }\end{array}$ & 1086 & 1086 & $97 \%$ & $99 \%$ \\
\hline $\begin{array}{l}\text { Neoscona nautica } \\
\text { isolate JTKK1 }\end{array}$ & $\begin{array}{l}\text { Neoscona nautica isolate, cytochrome oxidase } \\
\text { subunit I (COI) gene, partial genome }\end{array}$ & 1098 & 1098 & $99 \%$ & $99 \%$ \\
\hline $\begin{array}{l}\text { Crossopriza lyoni } \\
\text { isolate JTKK1 }\end{array}$ & $\begin{array}{l}\text { Crossopriza lyoni isolate, cytochrome oxidase } \\
\text { subunit I (COI) gene, partial genome }\end{array}$ & 346 & 390 & $96 \%$ & $73 \%$ \\
\hline
\end{tabular}

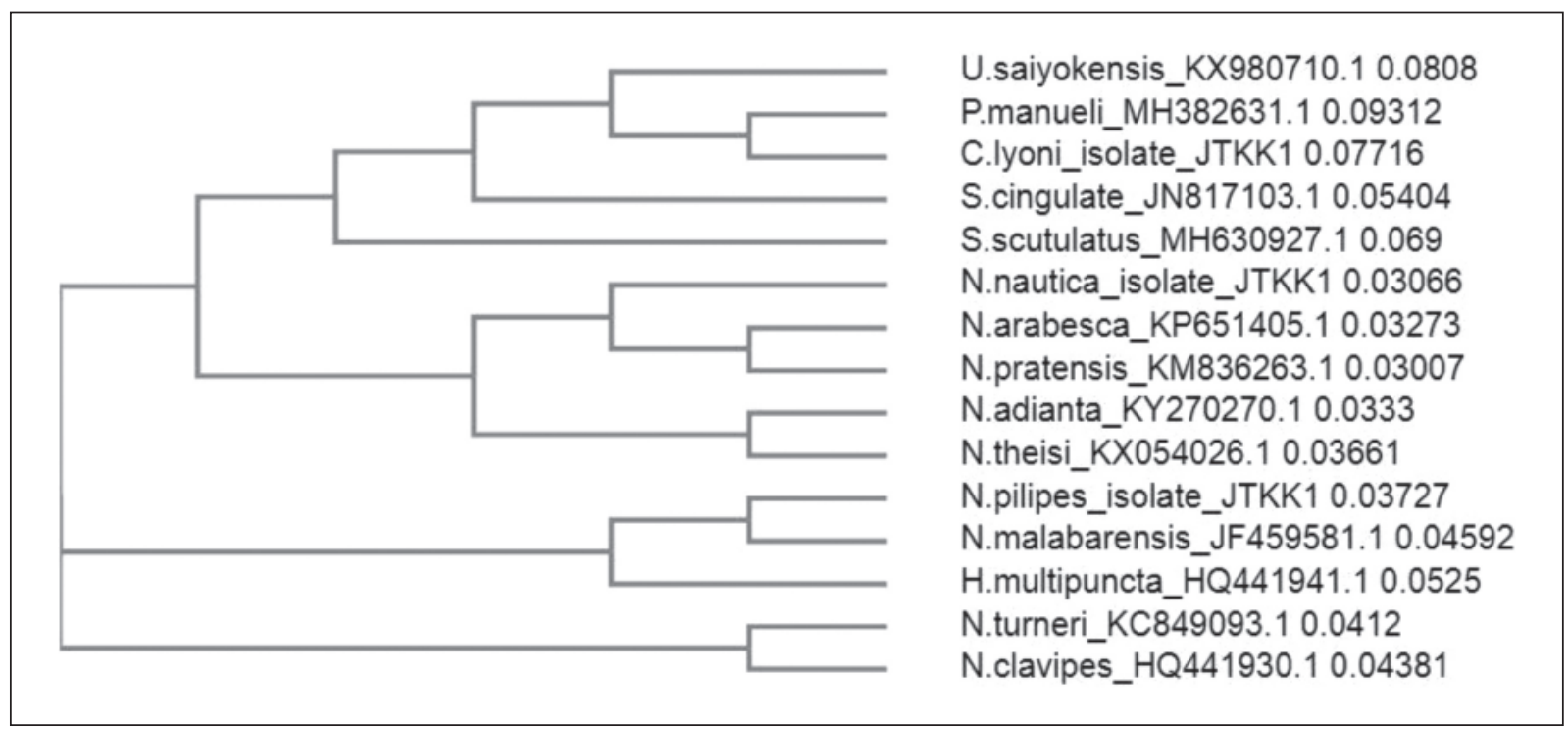

Fig. 10. The phylogenetic tree from the primer pairs of LCO1490A-Chelicerate Reverse 1 shows the close relatedness based on genetic distance between $N$. nautica isolate JTKK1 (0.03066) and $N$. pilipes isolate JTKK1 (0.03727) as compared to C. lyoni isolate JTKK1 (0.07716).

Despite the low similarity percentage, it is still acceptable for further phylogenetic analysis. In conclusion, the quality of these analyses is definitely improved with the appliance of PCRsequencing. Interestingly, this finding was corroborated by Rhennetta (2015) in which the primer pairs containing LCO1490A-Chelicerate Reverse 1 and LCO1490A-Chelicerate Reverse 2 were able to barcode nine different species of spiders.

\section{Phylogenetic tree analysis}

Phylogenetic trees were constructed and recovered using Clustal Omega as illustrated in Figure 10 and Figure 11 to infer the evolutionary relationship between each species. The results from the phylogenetic analyses indicated that all different species and control datasets were clearly separated. The numbers that indicate after the name of the samples in the figures depict the genetic distance of the samples. The genetic distances between Neoscona nautica and Nephila pilipes is more than 0.001 as depicted in Figure 10 and Figure 11, thus can be classified as two different species. Conversely, if two samples are diverged from a same node with genetic distance that less than 0.001 , it can be determined that both samples belong to the same species with only slight differences in DNA sequence. These comparisons did not show any close match in species-level for all the analysed samples.

The genetic distance between Nephila pilipes isolate JTKK1 and Neoscona nautica isolate JTKK1 is relatively close in comparison to Crossopriza lyoni isolate JTKK1, respectively. This shows that $N$. pilipes and $N$. nautica are closely related to each other compared to $C$. lyoni. It also reflects the fact that there is a much lower level of genetic distance of a species among the members of the same family. It is noticeable that the evolution of each species is distinguishable using different primer pairs. It can be inferred that there is a little variation in terms of the gene sequence during the alignment of DNA fragment with each other. 


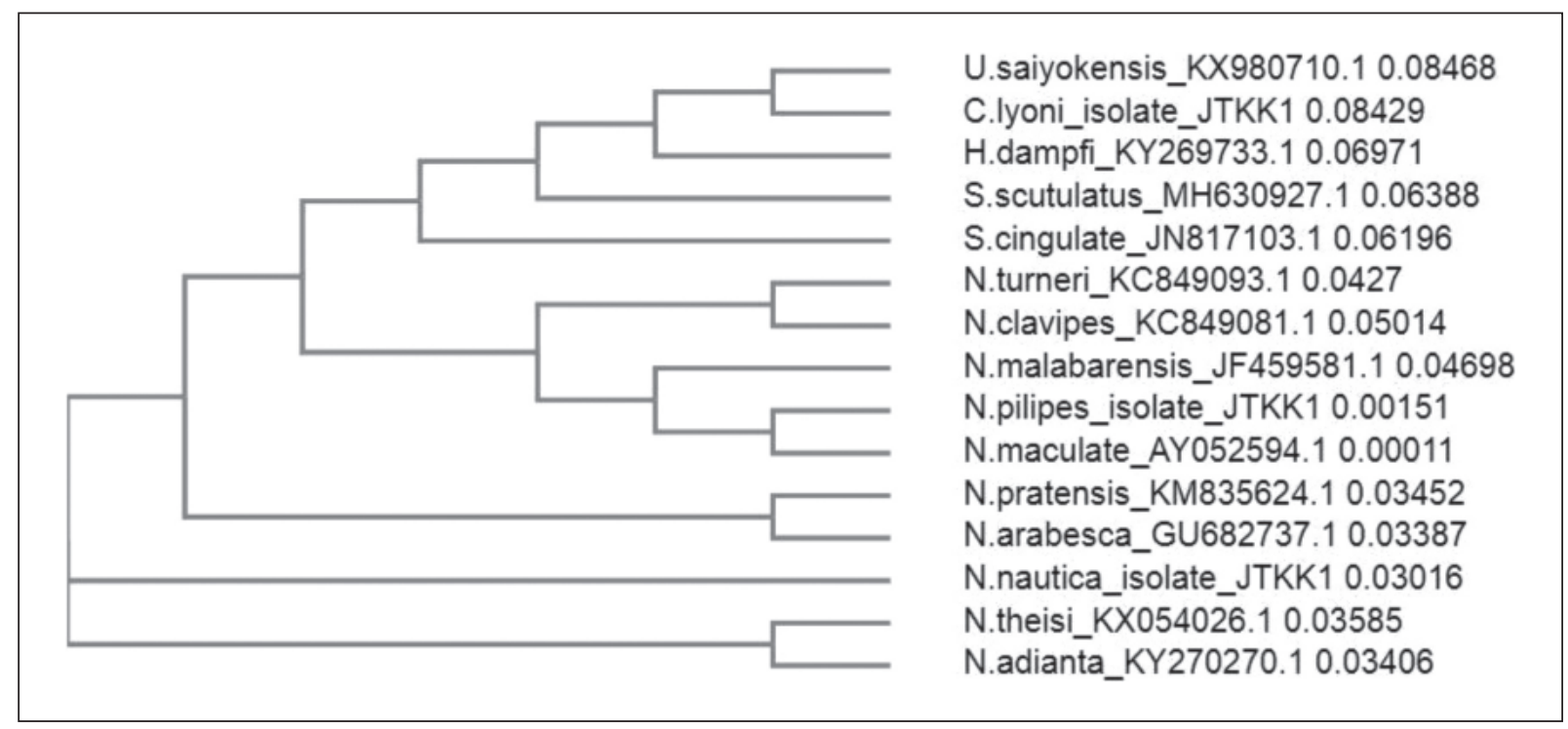

Fig. 11. The phylogenetic tree from the primer pairs of LCO1490A-Chelicerate Reverse 2 indicates the close relatedness based on genetic distance between $N$. nautica isolate JTKK1 (0.03016) and N. pilipes isolate JTKK1 (0.00151) as compared to C. lyoni isolate JTKK1 (0.08429).

\section{CONCLUSION}

The present study shows that COI gene exhibits variability with reference to the spider samples and protocol used. The generation of the COI gene sequence allows the assignation of the analyzed spider specimens to the appropriate species namely, Nephila pilipes, Neoscona nautica and Crossopriza lyoni via DNA sequencing analysis and Basic Local Alignment Search Tool. Spin column based extraction protocol was proven to be one of the versatile genomic DNA extraction techniques for the identification of the specimens, as amplification of the DNA sample was efficient in generating COI fragments for DNA sequencing and phylogenetic analysis. Clearly, this study offers an accurate molecular identification that outdoes those morphological based techniques for the identification purpose of spider species. The discriminating and resolving potentials of the designed primer pairs have been proven as they were able to amplify the COI gene sequence region thus, offering a more reliable identification of the respective species. The species-level molecular phylogeny of the selected spiders has also been clearly elucidated through this study as part of the investigation of their relationships and evolutionary history.

\section{ACKNOWLEDGMENTS}

This work was supported by the Fundamental Research Grant Scheme (FRGS) under a grant number of FRGS/1/2017/STG05/UNIMAP/03/1 from the Ministry of Education Malaysia. The author would also like to thank Universiti Malaysia Perlis (UniMAP) for the facilities provided and gratefully acknowledge the support.

\section{REFERENCES}

Altschul, S.F., Gish, W., Miller, W., Myers, E.W. \& Lipman, D.J. 1990. Basic Local Alignment Search Tool. Journal of Molecular Biology, 215: 403-410.

Anjali. 2015. Genetic Studies on Spiders of Agra Region (Ph.D.). Deemed University.

Coddington, J.A. \& Levi, H.W. 1991. Systematics and evolution of spiders (Araneae). Annual Review of Ecology and Systematics, 22: 565592.

Foelix, R.F. 2011. Biology of Spiders. 3rd Ed. Oxford University Press, New York.

Huber, B.A. \& Gonzalez, A.P. 2001. A new genus of pholcid spider (Araneae, Pholicidae) endemic to western Cuba, with a case of female genitalic dimorphism. American Museum Novitates, 3329: $1-23$. 
Jocque, R. 2002. Genetic polymorphism: a challenge for taxonomy. Journal of Arachnology, 30: 298306.

Max, B., Niall, J.M., Mark, L.T.B. \& Paul, W.S. 2016. DNA extraction from spider webs. Conservation Genet Resource. Conservation Genetics Resources, 8: 219-221.

Pei, Y.L., John, C., Chih, Y.H. \& Kim, Y.H. 2012. Agarose gel electrophoresis for the separation of DNA fragments. Journal of Visualized Experiments, 62: 3923.

Rhennetta, B.J. 2015. Primer Efficacy in the DNA Barcoding of Spiders (Honors). University of Northern Iowa.

Ramakrishnaiah, T.N., Ramakrishna, S. \& Jayaprakash, S. 2015. Evaluation of genomic DNA spin-50 method for amplification of ITS2 gene in spiders. International Journal of Zoology and Research, 5(4): 5-10.

Romer, L. \& Scheibel, T. 2008. The elaborate structure of spider silk: structure and function of a natural high performance fiber. Prion, 2(4): 154-161.
Rowan, D.H.B. \& Paul, D.N.H. 2005. Identifying spiders through DNA barcodes. Canadian Journal of Zoology, 83(3): 481-491.

Sebastian, P.A. \& Peter, K.V. 2009. Spiders of India. Universities Press (India) Private Limited, Hyderabad.

Sharma, P. \& Kobayashi, T. 2014. Are "universal" DNA primers really universal? Journal of Applied Genetics, 55(4): 485-496.

Tibayrenc, M. 2005. Bridging the gap between molecular epidemiologists and evolutionists. Trends in Microbiology, 13: 575-580.

White, T.J., Bruns, T., Lee, S. \& Taylor, J. 1990. Amplification and direct sequencing of fungal ribosomal RNA genes for phylogenetics. In: PCR Protocols: A Guide to Methods and Applications. M.A. Innis, D.H. Gelfand, J.J. Sninsky and T.J. White. Academic Press, USA. pp. 315-322.

Wise, D.H. 1993. Spiders in Ecological Webs. Cambridge University Press, Cambridge. 